Supplement of Atmos. Meas. Tech., 8, 2347-2358, 2015

http://www.atmos-meas-tech.net/8/2347/2015/

doi:10.5194/amt-8-2347-2015-supplement

(C) Author(s) 2015. CC Attribution 3.0 License.

(c) (1)
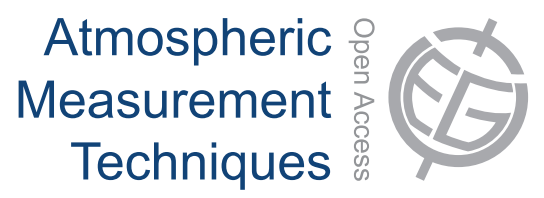

Supplement of

\title{
Determination of atmospheric organosulfates using HILIC chromatography with MS detection
}

\author{
A. P. S. Hettiyadura et al.
}

Correspondence to: E. A. Stone (betsy-stone@uiowa.edu.)

The copyright of individual parts of the supplement might differ from the CC-BY 3.0 licence. 


\section{Extended discussion of the observation and formation of multiple isomers of organosulfates with formulas $\mathrm{C}_{5} \mathrm{H}_{11} \mathrm{O}_{7} \mathrm{~S}^{-}, \mathrm{C}_{5} \mathrm{H}_{9} \mathrm{O}_{7} \mathrm{~S}^{-}$, and $\mathrm{C}_{5} \mathrm{H}_{7} \mathrm{O}_{7} \mathrm{~S}^{-}$}

Proposed structures for organosulfates with molecular formulas of $\mathrm{C}_{5} \mathrm{H}_{11} \mathrm{O}_{7} \mathrm{~S}^{-}(\mathrm{m} / z 215)$, $\mathrm{C}_{5} \mathrm{H}_{9} \mathrm{O}_{7} \mathrm{~S}^{-}\left(\mathrm{m} / z\right.$ 213) and $\mathrm{C}_{5} \mathrm{H}_{7} \mathrm{O}_{7} \mathrm{~S}^{-}(\mathrm{m} / z 211)$ are shown in Tables $\mathrm{S} 1, \mathrm{~S} 2$ and $\mathrm{S} 3$, respectively. One enantiomeric form of each isomer is shown. The $\mathrm{BEH}$ amide column is achiral and will not resolve enantiomers, but is capable of resolving diastereomers and conformational isomers. The proposed structures for $\mathrm{C}_{5} \mathrm{H}_{11} \mathrm{O}_{7} \mathrm{~S}^{-}$are based upon the acid-catalyzed ring-opening of each of the four isomers of IEPOX observed as photooxidation products of isoprene: $\beta 1$-IEPOX, $\beta 4$-IEPOX, $\delta 1$-IEPOX and $\delta 4-$ IEPOX (Paulot et al., 2009). In the presence of acid and sulfate, IEPOX will undergo ring-opening with sulfate as a nucleophile, forming methyltetrol sulfates (Surratt et al., 2010). The expoxide ring opening is regioselective; the nucleophile preferentially attacks tertiary carbons, inverting the stereochemistry at this carbon. If a tertiary carbon is part of the epoxide, the nucleophile preferentially attacks the least substituted carbon (i.e., primary > secondary).

Considering the ring-opening of the four IEPOX isomers elucidated by Paulot et al. (2009) and the regioselectivity of epoxide ring opening, four major isomers of $\mathrm{C}_{5} \mathrm{H}_{11} \mathrm{O}_{7} \mathrm{~S}^{-}(\mathrm{m} / z 215)$ are expected to form, as shown in Table S1. Specifically, $\beta 1$-IEPOX yields product $1, \beta 4$-IEPOX yields product $1, \delta 1$ IEPOX yields products $\mathbf{3}$ and $\mathbf{4}$, and $\delta 4$-IEPOX yields products $\mathbf{1}$ and $\mathbf{2}$. These major products are expected to correspond to the four major peaks observed for $\mathrm{C}_{5} \mathrm{H}_{11} \mathrm{O}_{7} \mathrm{~S}^{-}(\mathrm{m} / z 215)$ in Figure 4. Additional products 5-8 are suggested to form as minor products due to nucleophile attack on the secondary carbon of $\beta 1$-IEPOX, $\beta 4$-IEPOX and $\delta 1$-IEPOX, and the primary carbon of $\delta 4$-IEPOX. These expected minor products likely contribute to the two minor chromatographic peaks for $\mathrm{C}_{5} \mathrm{H}_{11} \mathrm{O}_{7} \mathrm{~S}^{-}(\mathrm{m} / z 215)$ eluting at 4.51 and 4.81 minutes in Figure 4.

Organosulfates with the formula $\mathrm{C}_{5} \mathrm{H}_{9} \mathrm{O}_{7} \mathrm{~S}^{-}(\mathrm{m} / z 213)$ have been shown to form in chamber studies with isoprene as the precursor gas (Surratt et al., 2008) and are related to the organosulfates with formula $\mathrm{C}_{5} \mathrm{H}_{11} \mathrm{O}_{7} \mathrm{~S}^{-}(\mathrm{m} / z 215)$ by loss of $\mathrm{H}_{2}$ and an increase of one unit of unsaturation. It is plausible to consider that one of the primary alcohols in the $\mathrm{C}_{5} \mathrm{H}_{11} \mathrm{O}_{7} \mathrm{~S}^{-}(\mathrm{m} / z 215)$ organosulfate is oxidized to an aldehyde in 
the atmosphere, losing one unit of unsaturation and giving the product $\mathrm{C}_{5} \mathrm{H}_{9} \mathrm{O}_{7} \mathrm{~S}^{-}(\mathrm{m} / z 213)$. The resulting oxidation product for either $\mathbf{1}$ or $\mathbf{2}$ is a $\gamma$-hydroxyaldehyde, which is in equilibrium with the intramolecular hemiacetal form (a.k.a. lactol form) shown in Table S2. The formation of five- and sixmembered ring is thermodynamically favored over the straight-chain form. Hence, products $\mathbf{9}-\mathbf{1 6}$ in Table $\mathrm{S} 2$ are proposed as structures for $\mathrm{C}_{5} \mathrm{H}_{9} \mathrm{O}_{7} \mathrm{~S}^{-}(\mathrm{m} / z 213)$, and are suggested to form from the oxidation of products 1 and 2 to an aldehyde, followed by intramolecular hemiacetal formation. The order of elution of $\mathrm{C}_{5} \mathrm{H}_{9} \mathrm{O}_{7} \mathrm{~S}^{-}(\mathrm{m} / z, 213)$ and $\mathrm{C}_{5} \mathrm{H}_{11} \mathrm{O}_{7} \mathrm{~S}^{-}(\mathrm{m} / z, 215)$ from the $\mathrm{BEH}$ amide column supports this structural assignment, as the proposed $\mathrm{C}_{5} \mathrm{H}_{9} \mathrm{O}_{7} \mathrm{~S}^{-}(\mathrm{m} / \mathrm{z}, 213)$ product contains one less hydroxyl group, decreasing the strength of hydrogen-bonding interactions with the stationary phase compared to $\mathrm{C}_{5} \mathrm{H}_{11} \mathrm{O}_{7} \mathrm{~S}^{-}(m / z 215)$, causing it to elute from the column earlier.

Similarly, organosulfates with formulas $\mathrm{C}_{5} \mathrm{H}_{7} \mathrm{O}_{7} \mathrm{~S}^{-}(\mathrm{m} / \mathrm{z} 211)$ have been shown to form in chamber studies with isoprene as the precursor gas (Surratt et al., 2008) and are related to the organosulfates with formula $\mathrm{C}_{5} \mathrm{H}_{9} \mathrm{O}_{7} \mathrm{~S}^{-}(\mathrm{m} / 2$ 213) with an increase of one unit of unsaturation. It is plausible to consider that the $\gamma$-hydroxyaldehyde from products $\mathbf{1}$ and $\mathbf{2}$ is further oxidized to a carboxylic acid in the atmosphere, by addition of oxygen. The resulting product is a $\gamma$-hydroxycarboxylic acid, which in the presence of dilute acids immediately undergoes cyclization and loss of water to form a lactone shown in Table S3. The formation of the five-membered lactone ring imparts stability on the molecule compared to the straight chain form, making the ring the thermodynamically favored product. Hence, products $\mathbf{1 7}-\mathbf{2 4}$, shown in Figure $\mathrm{S} 2$ are proposed structures for $\mathrm{C}_{5} \mathrm{H}_{7} \mathrm{O}_{7} \mathrm{~S}^{-}(\mathrm{m} / z 211)$. The order of elution from the BEH amide column again supports this assignment, with $\mathrm{C}_{5} \mathrm{H}_{7} \mathrm{O}_{7} \mathrm{~S}^{-}(\mathrm{m} / z 211)$, having only one fewer hydroxyl group than $\mathrm{C}_{5} \mathrm{H}_{9} \mathrm{O}_{7} \mathrm{~S}^{-}\left(\mathrm{m} / z\right.$ 213) and two fewer hydroxyl groups than $\mathrm{C}_{5} \mathrm{H}_{11} \mathrm{O}_{7} \mathrm{~S}^{-}(\mathrm{m} / z$ 215). With fewer hydrogen-bond donor sites, the strength of the interactions between $\mathrm{C}_{5} \mathrm{H}_{7} \mathrm{O}_{7} \mathrm{~S}^{-}(\mathrm{m} / z 211)$ and the stationary phase decrease, causing it to elute earlier. 
Table S1: Proposed structures for $\mathrm{C}_{5} \mathrm{H}_{11} \mathrm{O}_{7} \mathrm{~S}^{-}(\mathrm{m} / z$ 215) that can be formed by acid catalyzed IEPOX ring opening in the presence of sulfate. Only one enantiomeric form of each isomer is shown.

\begin{tabular}{|c|c|}
\hline Major isomers of $\mathrm{C}_{5} \mathrm{H}_{11} \mathrm{O}_{7} \mathrm{~S}^{-}(\mathrm{m} / \mathrm{z} 215)$ & Minor isomers of $\mathrm{C}_{5} \mathrm{H}_{11} \mathrm{O}_{7} \mathrm{~S}^{-}(\mathrm{m} / \mathrm{z} 215)$ \\
\hline$(2 S, 3 R)$-1,3,4-trihydroxy-2-methylbutyl-2-sulfate & $(2 S, 3 R)$-1,3,4-trihydroxy-3-methylbutyl-2-sulfate \\
\hline (2R,3R)-1,3,4-trihydroxy-2-methylbutyl-2-sulfate & (2R,3R)-1,3,4-trihydroxy-3-methylbutyl-2-sulfate \\
\hline (2R,3R)-2,3,4-trihydroxy-3-methylbutyl sulfate & $(2 R, 3 R)$-2,3,4-trihydroxy-2-methylbutyl sulfate \\
\hline$(2 S, 3 R)-2,3,4$-trihydroxy-3-methylbutyl sulfate & (2R,3S)-2,3,4-trihydroxy-2-methylbutyl sulfate \\
\hline
\end{tabular}


Table S2: Proposed structures for $\mathrm{C}_{5} \mathrm{H}_{9} \mathrm{O}_{7} \mathrm{~S}^{-}(\mathrm{m} / z$ 213), that are proposed to form from the oxidation of a primary alcohol in $\mathrm{C}_{5} \mathrm{H}_{11} \mathrm{O}_{7} \mathrm{~S}^{-}(\mathrm{m} / 2$ 215) to an aldehyde, followed by intramolecular hemiacetal formation. Only one enantiomeric form of each isomer is shown.

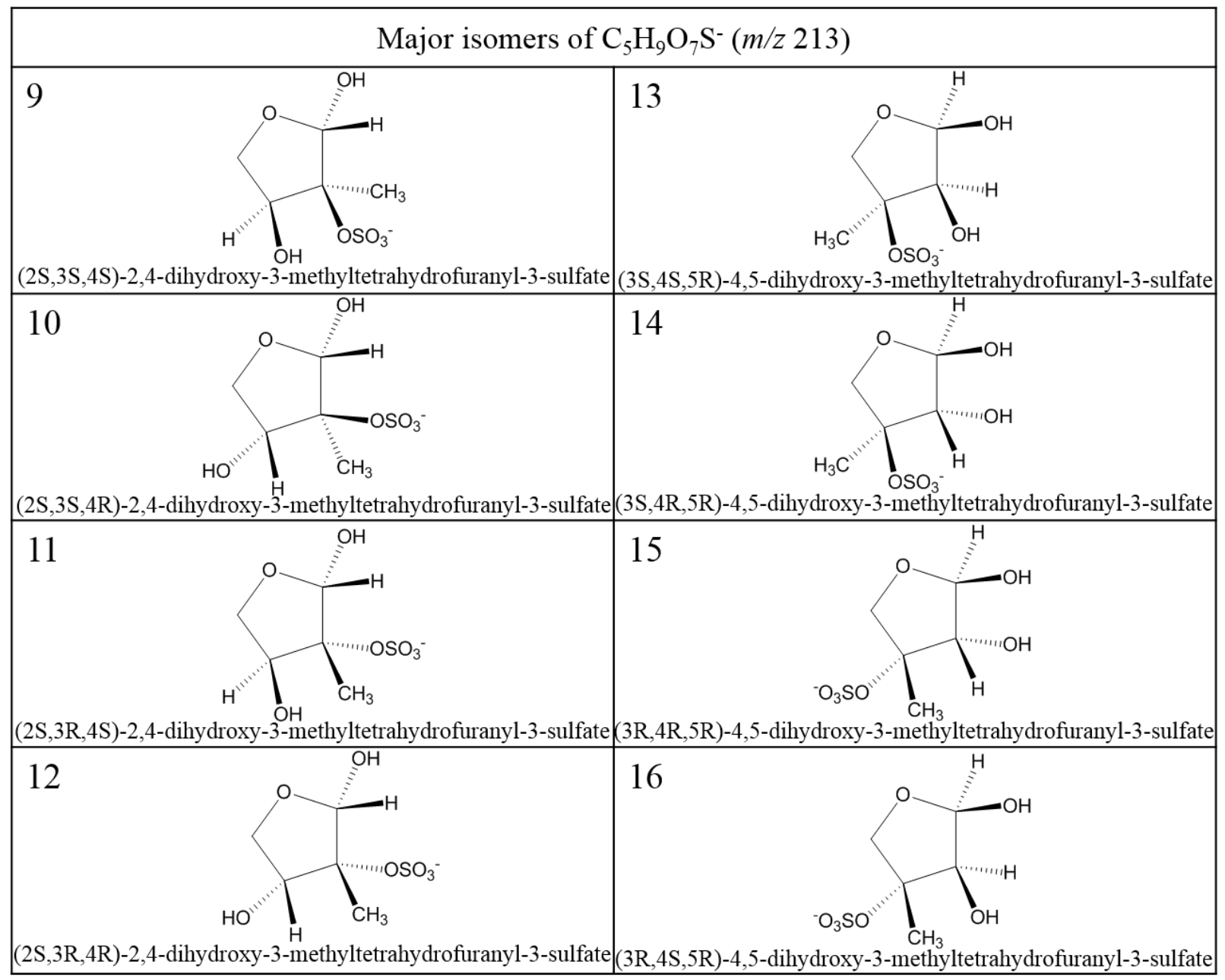


Table S3: Proposed structures for $\mathrm{C}_{5} \mathrm{H}_{7} \mathrm{O}_{7} \mathrm{~S}^{-}(\mathrm{m} / z$ 211) that is proposed to form from the oxidation of a primary alcohol in $\mathrm{C}_{5} \mathrm{H}_{11} \mathrm{O}_{7} \mathrm{~S}^{-}(\mathrm{m} / z 215)$ to a carboxylic acid, followed by intramolecular lactone formation and loss of water. Only one enantiomeric form of each isomer is shown.

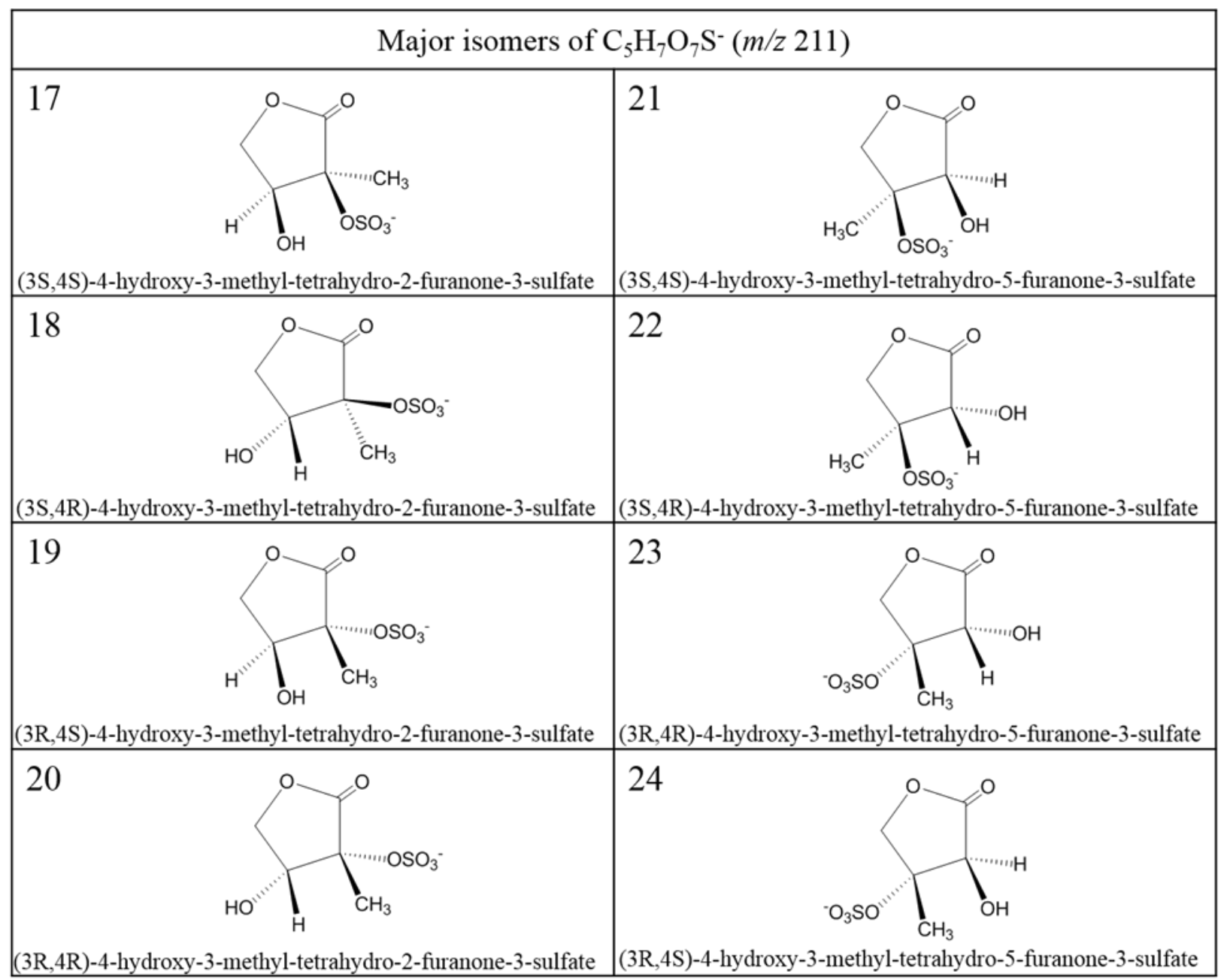




\section{References}

Paulot, F., Crounse, J. D., Kjaergaard, H. G., Kürten, A., St. Clair, J. M., Seinfeld, J. H. and Wennberg, P. O.: Unexpected epoxide formation in the gas-phase photooxidation of isoprene, Science, 325, 730733, 10.1126/science.1172910, 2009.

Surratt, J. D., Gomez-Gonzalez, Y., Chan, A. W. H., Vermeylen, R., Shahgholi, M., Kleindienst, T. E., Edney, E. O., Offenberg, J. H., Lewandowski, M., Jaoui, M., Maenhaut, W., Claeys, M., Flagan, R. C. and Seinfeld, J. H.: Organosulfate formation in biogenic secondary organic aerosol, Journal of Physical Chemistry A, 112, 8345-8378, 10.1021/jp802310p, 2008.

Surratt, J. D., Chan, A. W. H., Eddingsaas, N. C., Chan, M., Loza, C. L., Kwan, A. J., Hersey, S. P., Flagan, R. C., Wennberg, P. O. and Seinfeld, J. H.: Reactive intermediates revealed in secondary organic aerosol formation from isoprene, Proceedings of the National Academy of Sciences, 107, 66406645, 10.1073/pnas.0911114107, 2010. 